\title{
a-Mangostin Effect on Inhibition Development Stadium and Globin Accumulation Against Plasmodium falciparum
}

\author{
Hadi Kuncoro ${ }^{1 *}$, Aty Widyawaruyanti ${ }^{2}$, Taslim Ersam ${ }^{3}$
}

\section{Hadi Kuncoro ${ }^{1 *}$, Aty Widyawaruyanti², Taslim Ersam ${ }^{3}$}

\begin{abstract}
'Laboratorium Penelitian dan Pengembangan Kefarmasian FARMAKA TROPIS, Fakultas Farmasi, Mulawarman University, Samarinda 75119, East Kalimantan, INDONESIA. ${ }^{2}$ Department of Pharmacognosy and Phytochemistry, Faculty of Pharmacy, Airlangga University, Surabaya, 60286, Indonesia, Center for Natural Product Medicine Research and Development, Institute of Tropical Disease, Airlangga University, Surabaya 60115, INDONESIA. ${ }^{3}$ Department of Chemistry, Faculty of Mathematics and Natural Sciences, Institut Teknologi Sepuluh November, Kampus ITS-Sukolilo, Surabaya 60111, INDONESIA.
\end{abstract}

\section{Correspondence}

\section{Hadi Kuncoro}

Laboratorium Penelitian dan Pengembangan Kefarmasian FARMAKA TROPIS, Fakultas Farmasi, Mulawarman University, Samarinda 75119,

East Kalimantan, INDONESIA.

Phone no : +62541739491

E-mail: hadikuncoro@farmasi.unmul.ac.id History

- Submission Date: 06-12-2017;

- Review completed: 05-03-2018;

- Accepted Date: 03-05-2018

DOI : 10.5530/pj.2018.4.132

Article Available online

http://www.phcogj.com/v10/i4

\section{Copyright}

(c) 2018 Phcog.Net. This is an openaccess article distributed under the terms of the Creative Commons Attribution 4.0 International license.

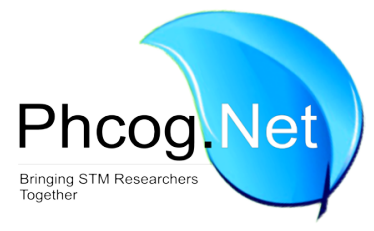

\begin{abstract}
$\alpha$-Mangostin is a widely reported group of Xanthone compounds from the Clusiaceae family of 40 genera and over 1000 species spread across the tropics and subtropics area. The Objective for determine effect of $\alpha$-mangostin from Garcinia tetrandra Pierre stem bark against development stadium inhibition and globin accumulation of Plasmodium falciparum. Inhibition stadium development assay used based on the Rosenthal method. Plasmodium falciparum parasitic globin accumulation assay. Globin accumulation assay used the highest concentration of in vitro antimalarial test using SDS-PAGE with positive control E-64 and $\alpha$-mangostin were incubated together with the malaria parasite during $24 \mathrm{~h}$. Result of Inhibition stadium development of Plasmodium falciparum against $\alpha$-mangostin show inhibition from development stadium of the malaria parasite Plasmodium falciparum, Electrophoresis show globin accumulation from electrophoresis followed by staining using Coomassie brilliant blue. $\alpha$-mangostin showed inhibition the growth of malaria parasite Plasmodium falciparum with dose $10 \mu \mathrm{g} / \mathrm{ml}$ is expected to occur a large accumulation of globin, which can be viewed both morphologically and by the method of SDS-PAGE.

Key word: Garcinia tetrandra, $\alpha$-mangostin, Plasmodium falciparum, Development stage inhibition, SDS-PAGE.
\end{abstract}

\section{INTRODUCTION}

a-Mangostin is a widely reported group of xanthone compounds from the Clusiaceae family of 40 genera and over 1000 species spread across the tropics and subtropics area. One species of Garcinia (Cluseaceae) which is still rarely studied its chemical content is Garcinia tetrandra, Based on research on G. tetrandra previously reported, has isolated several compounds of xanthone from various parts one of them is $\alpha$-mangostin. ${ }^{1} \alpha$-Mangostin is a xanthone that show various biological activities, and numerous reports have shown its efficacy in cancer prevention and inhibition. $^{2}$ antiperoxidative effect in brain tissue preparations probably through its properties as a freeradical scavenger, ${ }^{3}$ an effective antibacterial agent against S. epidermidis RP62A without posing any risk for the development of resistance, ${ }^{4}$ antioxidant, antiinfective, anticarcinogenic, and antidiabetic activities, neuroprotective, hepatoprotective, and cardioprotective properties, among which the anticarcinogenic activity is the most promising 5,6 and promising antimalarial activity, ${ }^{7}$ Based on previous research report on in vitro growth inhibition assay of Plasmodium falciparum parasites against eight compounds isolated xanthones from Garcinia tetrandra Pierre stem bark, known $\alpha$-mangostin have $\mathrm{IC}_{50} 0.5 \times 10^{-3} \mu \mathrm{M}$, This is show smaller value of $\mathrm{IC}_{50}$ from chloroquine diphosphate with $\mathrm{IC}_{50}=3 \times 10^{-3} \mu \mathrm{M}$, This indicates that compounds

are potent to be followed up for new antimalarial drugs. ${ }^{9}$ In this report we focused on the mechanism of $\alpha$-mangostin as antimalarials to determine the development stadium inhibition and globin accumulation of $P$. falciparum.

\section{MATERIALS AND METHOD}

\section{Materials and chemicals}

Research samples: active component $\alpha$-mangostin isolated from Garcinia tetrandra Pierre stem bark comes from National park of Meru Betiri Jember, East Java. Malaria parasite P. falciparum 3D7 strain with certain parasitemia percentage and already synchronization. P. falciparum parasite 3D7 strain obtained from Eijkman institute of Molecular Biology, Jakarta. The materials used for breeding parasites: $\mathrm{NaCl}$ (Merck), RPMI 1640, HEPES buffer, $\mathrm{NaHCO}_{3}$, hypoxanthine (Merck), D-sorbitol (Sigma), gentamicin sulfate (Sigma), serum and Human blood cell O type, aquadest sterile for irrigation (Otsuka), Giemsa, and immersion oil.

\section{Instrument}

Instrument: Blue tip, yellow tip, culture tube, autoclave, oven, bottle (Scott-Duran), centrifuge tube, micro pipette (Soccorex dan Eppendorf), Laminar Air Flow (LAF/clean bench), microscope (Olympus
Cite this article: Kuncoro H, Widyawaruyanti A, Ersam T. $\alpha$-Mangostin effect on inhibition development stadium and globin accumulation against Plasmodium falciparum. Pharmacog J. 2018;10(4):783-8. 
$\mathrm{CH}-20$ ), object glass, disposable syringe, refrigerator, incubator, desiccator, candle, membrane filter $0,22 \mu \mathrm{m}$, cold centrifuge, Petridish, vacuum pump, stirrer, and water bath.

\section{Culture and sub culture procedure of Malaria Parasite P. falciparum}

This culture procedure is based on Trager and Jensen (1976) methods. ${ }^{10}$ The cultures are carried in the petridish and treated aseptically.

Erythrocytes infected with malaria parasites were centrifuged at $1500 \mathrm{rpm}$ for $5 \mathrm{~min}$ at $4^{\circ} \mathrm{C}$. The supernatant was then discarded. Packed cells are suspended with a new complete medium of equal volume to create a 50\% suspension and subsequently divided into new petridish. Then into the petridish added a complete medium and new erythrocytes (RBC 50\%) to form 5\% hematocrit. Furthermore, a thin smear, stained with giemsa to calculate the percent of parasitemia and sub-culture incubated again.

\section{Culture synchronization of P. falciparum}

For a test of antimalarial activity, parasites are required in the synchronous state of the ring stadium. Synchronization is done using $5 \%$ sorbitol. ${ }^{11}$

\section{Inhibition stadium development and globin accumulation assay.}

This method is based on the Rosenthal method. ${ }^{12}$ As the test material is a-mangostin compound from bark of $G$. tetrandra Pierre with concentration of $10 \mu \mathrm{g} / \mathrm{ml}$, that is the highest concentration used in in vitro antimalarial test. As a negative control is the solvent used to dissolve the test material, ie DMSO with a concentration of no more than $1 \%$. To investigate the accumulation of globin associated with inhibitory activity against protease cysteine enzymes was used positive control of E-64 compound with a concentration of $10 \mu \mathrm{M}$ (Molecular Weight $\mathrm{E}-64=357.4)$

Parasite ring stadium $\pm 1 \%$ parasitemia already synchronization cultured with the test material and controls using 24 -well culture plates. At certain h $(0,6,12,24,48$ and $72 \mathrm{~h})$ parasite-infected erythrocytes were taken, made a thin smear on a glass object, fixed with methanol, stained with Giemsa and photographed with a light microscope (Olympus $\mathrm{CH}-20$ ) with 10 x100 enlargment

Parasite ring stadium $\pm 5 \%$ parasitemia already synchronization cultured with the test material and controls. Negative controls used in SDS-PAGE are two kinds of parasites that were collected on $0 \mathrm{~h}$ (ring stadium) and the parasites that were collected on $24 \mathrm{~h}$ (to be developed into a schizont stadium). While the positive control E-64 and test substances were incubated together with the malaria parasite during $24 \mathrm{~h}$.

\section{RESULTS}

\section{Inhibition development stadium assay}

Assay against inhibition of development stadiums and parasitic morphological were conducted by in-vitro assay on a synchronized $P$. falciparum strain 3D7 culture, using 24-well culture plates and incubated at various time variations.

\section{Globin accumulation assay using SDS-PAGE}

Investigation of globin accumulation in the parasite $P$. falciparum conducted using SDS-PAGE. Image results of electrophoresis followed by staining using Coomassie brilliant blue. Accumulation of globin in the gel electrophoresis results of the malaria parasite P. falciparum (3D7 strain) were incubated with, $\alpha$-mangostin (1) (line 5), negative control (schizont stadium) (line 3) using petridish for $24 \mathrm{~h}$ starting from the ring stadium. Negative control (ring stadium) used to show that at zero $\mathrm{h}$ there has been no decision is a significant hemoglobin by malaria parasites (line 2). Control used to determine the position of globin, hemoglobin used for the culture of malaria parasites (line 6) and hemoglobin standard (Sigma) (line 7). Globin will appear at $\pm 16 \mathrm{kDa}$ position (line 1).

\section{DISCUSSION}

Development stadium and globin accumulation of parasites in this study is performed by in-vitro culture of $P$. falciparum 3D7 strain. 3D7 strain is included groups of strains that were sensitive (susceptible) against chloroquine.

Plasmodium taken from frozen deposits and cultured in vitro after thawing process. Generally, the life cycle of $P$. falciparum in vitro cultures ranges from 46 to $48 \mathrm{~h}$. The malaria parasite stadium begins at the ring stadium (from 0 to \pm 12 th $\mathrm{h}$ ). At $12 \mathrm{~h}$ the parasite has progressed into a trophozoite stadium and then turned into a schizon stadium at $24 \mathrm{~h}$. At the stadium of schizon began to occur parasitic core clavage process. Each core will develop into merozoites, then break and invade new erythrocytes. This process runs repeating from the 24th $\mathrm{h}$ to \pm 48 th $\mathrm{h}$.

Parasitic cultures used for testing are prepared in advance by synchronization. The purpose of this synchronization is to equalize the stadium of the parasite so that it can be seen at certain stadiums of the test substance will show inhibitory activity. Synchronization is performed by using sorbitol which serves to lyse all adult stadium malaria parasites (schizon stadium) but not in the younger stadiums (rings stadium). A more mature stadium there has been a change in increased permeability of the erythrocyte so that sorbitol can enter into erythrocytes, lyse and cause the death of the parasite.

In vitro assays were performed aseptically using a 24-well culture plate. a-mangostin compound was dissolved with DMSO with a concentration of $10 \mu \mathrm{g} / \mathrm{ml}$ in a micro well. The final concentration of DMSO in each micro well is $1 \%$, because at this concentration the solvent does not affect the growth of the parasite. ${ }^{13} \alpha$-Mangostin and negative control are subsequently incubated with a parasitic suspension according to the length of one growth cycle of $P$. falciparum. The evaluation was done by comparing the parasite stadiums and morphology between control and test substances. After incubation at $0,6,12,24,48$, and $72 \mathrm{~h}$, a thin blood smear was prepared from each micro well on the object glass, followed by a fixation process with methanol and stained using Giemsa. then counting the number of infected erythrocytes selected from the monotonous field of view and then photographed.

Stadium parasite on h-0 in Figure 1, at the start of incubation performed well in the negative control, $\alpha$-mangostin is the ring stadium. Ring stadium selected because at this stadium begin to occur making process hemoglobin of erythrocytes into the cytosol of the parasite, which is expected in the event of obstacles hydrolysis will occur globin maximum accumulation in the parasite food vacuole. Percent of initial parasitaemia while starting the incubation well to the test substance, the negative control and a positive control is $\pm 1 \%$. At $6^{\text {th }} \mathrm{h}$ the negative controls and $\alpha$-mangosteen still do not show any change; that is still in the ring stadium, While at the $12^{\text {th }} \mathrm{h}$, the parasite on the negative control appears to change from the ring stadium to adult stadium trophozoite. In its development to trophozoite, the parasite can be said to be metabolically active because at this stadium there is a great increase in hemoglobin removal from the host erythrocytes into the parasite and passed on to the food vacuole for digestion. ${ }^{14}$ Parasite grows normally into a schizon stadium in negative control in $24 \mathrm{~h}$, this proves there has been a process of hemoglobin degradation into heme and globin. The resulting heme has been polymerized by the parasite into a yellow malaria pigment that is hemozoin, while globin has been broken down into amino acids and transported into the cytoplasm for the biosynthesis of malaria parasite proteins.

$24 \mathrm{~h}$ after treatment shows Figure 2 that there has been inhibition of parasite development from ring stadium to stadium trophozoite. Parasites should grow normally would develop into schizont stadium at the $24^{\text {th }} \mathrm{h}$ as shown in the negative control. In addition, the parasites that are given 

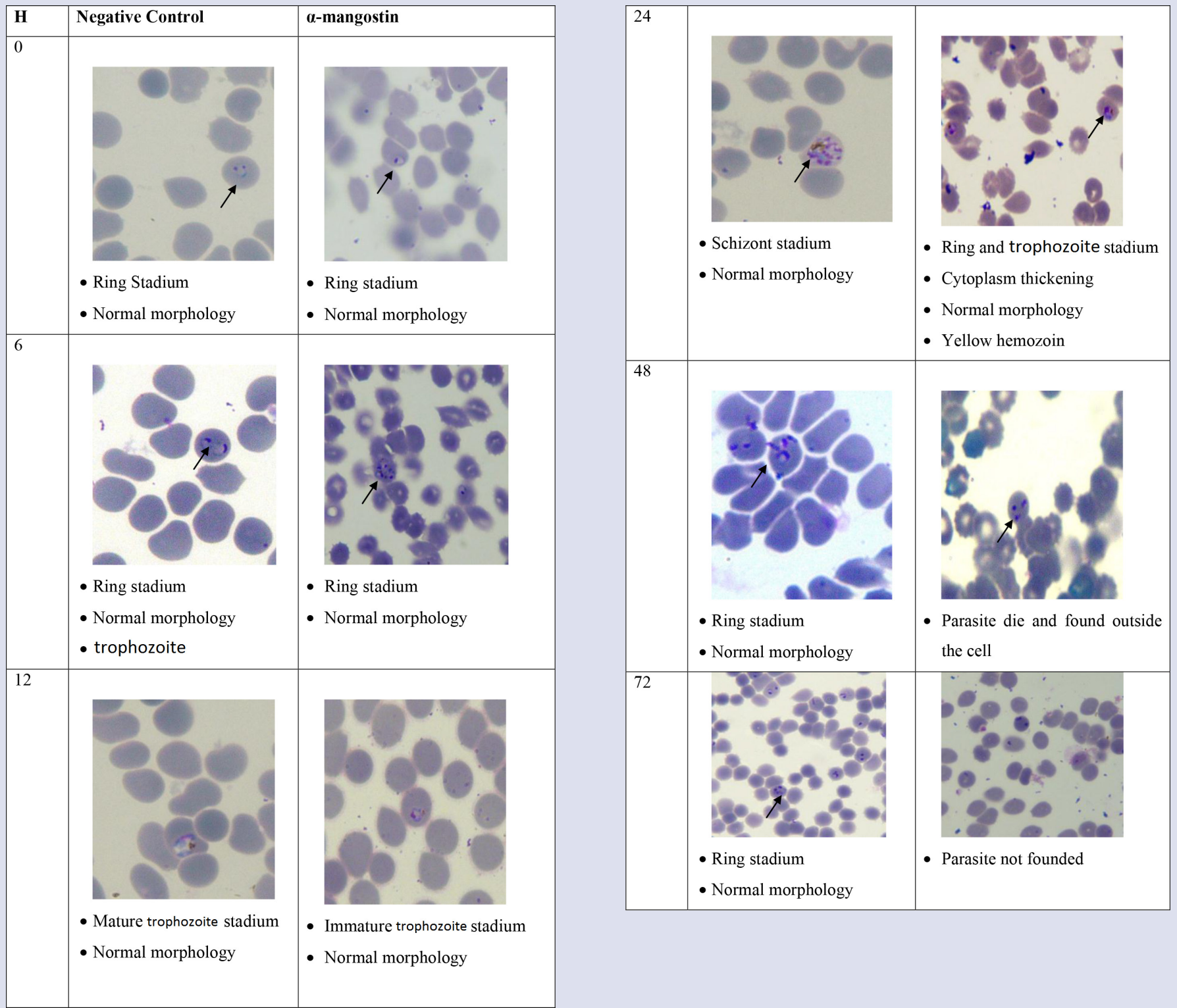

Figure 1: The development of stadium and morphology of $P$. falciparum (strain 3D7) incubated with negative control, a-mangostin (1) on 0, 6, 12, 24, 48 , and $72 \mathrm{~h}$; then made a thin smear, colored with giemsa and observed using a light microscope (Olympus CH-20) with 10x100 enlargment.

a-mangostin compound, on h- 24 morphologically abnormal swelling in the parasite food vacuole. This indicates that the $\alpha$-mangostin compounds cause the accumulation of globin in the parasite food vacuole. At 48-h observation, the parasite stadium at the negative control is the ring stadium, which means that at $24 \mathrm{~h}$ (an $\mathrm{h}$ to an $\mathrm{h}-24-48)$ has been ripening schizont into merozoites. This is shown by the percentage of parasitemia in the negative control which has significantly increased from $\pm 1 \%$ to $\pm 3 \%$, while the positive control or the parasite incubated with $\alpha$-mangostin percent decline in parasitemia. There is a presumption that the cysteine protease enzymes also play a role in solving the parasite cytoskeleton so that merozoites can go out and invade new erythrocytes. But this is still debated and is still looking for the possibility of other enzymes that also play a role in solving the parasite cytoskeleton. ${ }^{15}$ While the parasite is given the $\alpha$-mangostin it is not visible. In the observation of $72 \mathrm{~h}$, parasites stadium in the negative control is a ring with an increased percent stadium parasitemia to $\pm 4 \%$, while the parasites were incubated compounds 1 there are parasites not shown.

Based on the explanation, it can be concluded that the $\alpha$-mangostin compounds inhibit the development stadium of the malaria parasite $P$. falciparum, which causes delay in the development of the stadium into stadium trophozoite ring and schizont stadiums of growth caused by an abnormal morphology.

The principle of globin accumulation testing is similar to that of the parasitic stadium and morphological developmental resistance, but a-mangostin and control incubation is performed within the petridish to obtain more parasites. Positive control and $\alpha$-mangostin were incubated with parasite suspension for $24 \mathrm{~h}$ (starting at ring stadium). Incubation for $24 \mathrm{~h}$ is expected to occur maximum accumulation of globin, while 


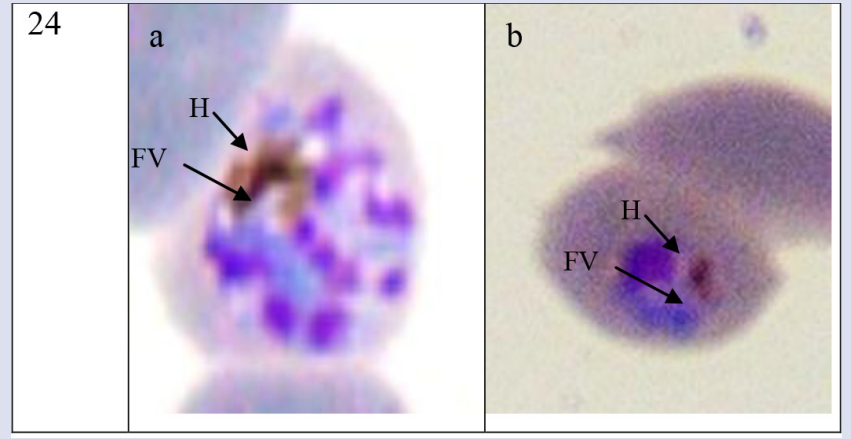

Figure 2: Morphology of $P$. falciparum food vacuole (strain 3D7) incubated with negative control, a-mangostin on $24 \mathrm{~h}$; then made a thin smear, colored with giemsa and photographed using a light microscope (Olympus) with $10 \times 100$ enlargement. Caption: FV = Food Vacuole and $\mathrm{H}=$ Hemozoin

the negative control used there are 2 kinds, malaria parasites that are collected directly at the $0 \mathrm{~h}$ (negative control $\mathrm{D}_{0}$, ring stadium) and parasites incubated for $24 \mathrm{~h}$ (stadiums of schizon). After $24 \mathrm{~h}$ incubation, parasite infected erythrocytes are dilated with saponins. Saponin is a neutral detergent that can lyse the erythrocyte membrane but does not lyse the parasitic membrane. ${ }^{16}$ Parasites then washed intensively with the aim of eliminating the erythrocyte cytosolic components. After that, sonication is done to destroy the parasitic membrane and remove the cytosolic components of the parasite including globin. Further parasite protein levels were determined using the Bradford method. ${ }^{17,18}$

The advantage of this method is the time required relatively fast but also sensitive. Materials used in the Bradford method including colouring reagent and bovine serum albumin (standart protein). Determination of these levels important to keep the samples coming into the SDS-PAGE wells equal, so that the non-degraded globin accumulation can be known to be valid. Then a similar concentration of parasitic proteins were measured, dissolved in SDS-PAGE buffer samples and electrophoresed using $15 \%$ acrylamide gel. After electrophoresis, the parasite protein was then identified by gel staining using coomasie briliant blue.

The SDS-PAGE to the accumulation of globin can be shown by band which is blue in the position of $\pm 16 \mathrm{kDa}$. After incubation at $24 \mathrm{~h}$, globin band founded on negative control. Morphologically, parasites were incubated with negative control at $24 \mathrm{~h}$ has turned into a stadium schizont. At the schizont stadium, hemoglobin taking process from host is reduced. Globin was already inside the parasite food vacuole to broken down into amino acids and immediately transported to the parasite cytosol for protein synthesis. Globin bands appears on the negative control probably due to there are still remnants of globin that has not been completely hydrolyzed within the parasite food vacuole. This indicates that the $\alpha$-mangostin compound it has a mechanism of action on the parasite food vacuole by inhibiting the degradation process of hemoglobin.

Normal trophozoite stadium there appears hemozoin in malaria parasite food vacuole and the cell nucleus in the cytoplasm. Presence of hemozoin in the food vacuole indicates that there has been making hemoglobin as a source of nutrients from the erythrocyte cytosol into food vacuoles and proteolysis converted into heme and globin. Furthermore, heme is toxic to the parasite has been detoxified into hemozoin as a product that is not toxic to the parasite.

$P$. falciparum another side cultures were incubated with $\alpha$-mangostin compounds also visible presence of food vacuoles containing hemozoin,

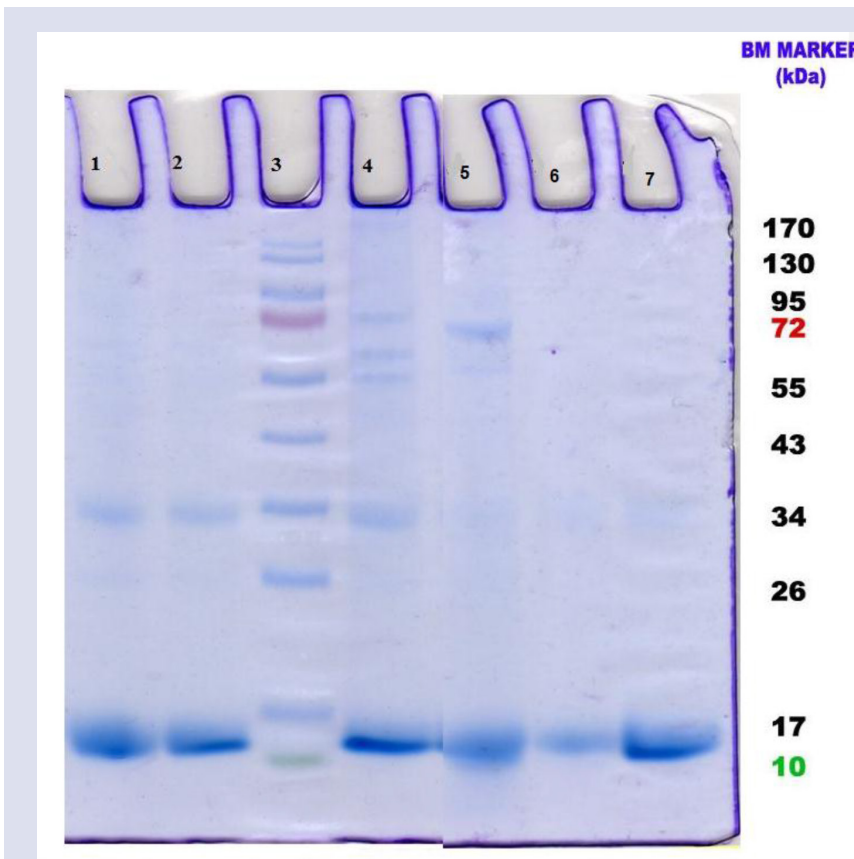

Figure 3: Accumulation of globin in the gel electrophoresis results of the malaria parasite $P$. falciparum (3D7 strain). Globin will appear at \pm $16 \mathrm{kDa}$ position,Positive control E-64 after $24 \mathrm{~h}$ incubation (Sigma, catalogue no. E-3132) (line 1), hemoglobin used for the culture of malaria parasites (line 2), Marker Protein Broad spectrum (line 3), a-mangostin (line 4), Negative control after $24 \mathrm{~h}$ incubation (line 5), Control of $\mathrm{D}_{0}$ (incubation start times on ring stadium) (line 6). and hemoglobin standard (Sigma) (line 7).

similar to that observed in negative controls. This means that the heme detoxification process took place normally. From explanation can be concluded that the compound on h 12 and 24 h, with $\mathrm{IC}_{50}$ does not indicate the occurrence of organelle damage and inhibition of hemozoin formation.

SDS-PAGE results on globin accumulation can be shown in the presence of black band (band) at position $16 \mathrm{kDa} .{ }^{1}$ In addition, the position of the globin band can also be demonstrated by using standard hemoglobin (Figure 3, line 7) and hemoglobin from erythrocytes used for parasitic cultures (Figure 3 , line 2). At the zero $h$ (negative control $\mathrm{D}_{0}$ ) represents the initial incubation at the ring stadium (Figure 3, line 6), indicating that there has been not significant globin accumulation. At the ring stadium, the process of taking hemoglobin from the erythrocyte cytosol into the parasite begins to occur. ${ }^{14}$ However, hemoglobin is still in the parasite cytosol because in the ring stadium has not formed vacuole food.

After $24 \mathrm{~h}$ incubation, a negative control was found on globin in figure 3 , line 5. In an experiment conducted by Rosenthal, the globin band is also found in negative controls. Morphologically, the parasite incubated with negative control at $24 \mathrm{~h}$ has turned into a schizon stadium. At the stadium of schizon, the process of taking hemoglobin from the host has decreased. Most globin is already inside the parasitic food vacuole to be broken down into amino acids and immediately transported to the parasite cytosol for the purpose of protein synthesis. The emergence of the globin band on negative control is probably due to the presence of globin remnants that have not been perfectly hydrolyzed inside the parasitic food vacuole. ${ }^{20}$

On the E-64 positive control (Figure 3, line 1) found globin band with highest intensity. At $24 \mathrm{~h}$, the parasite has progressed into trophozoite 
stadium accompanied by swelling in the abnormal parasitic food vacuoles, suggesting an un-degraded globin accumulation, while the parasite given a-mangostin (Figure 3, line 4 ) there is a globin band. This indicates the presence of globin in the malaria parasite, this is in accordance with the testing of developmental stadiums in which the parasite is delayed at the trophozoite stadium which means there is still accumulation of globin in the malaria parasite food vacuole. The abnormal swelling of malarial parasite food vacuoles is a specific parameter against the inhibition of proteist cysteine enzyme that correlates with inhibition of the globin hydrolysis process. ${ }^{19}$

Parasites in the early stadiums (ring stadium) begin to take the hemoglobin host into the parasite cytosol and in the ring stadium has not formed parasitic food vacuoles. Along with the development of the parasitic stadium (into trophozoite stadium), an increase in metabolism also increases the taking of hemoglobin of the host into the cytosol to be passed on to the parasitic food vacuole. ${ }^{14}$

The dose of $\alpha$-mangostin used in this study is a potent dose $(10 \mu \mathrm{g} / \mathrm{ml})$ inhibiting the growth of malaria parasite $P$. falciparum with the use of this dose is expected to occur a large accumulation of globin, which can be viewed both morphologically and by the method of SDS-PAGE.

The parasite incubated with $\alpha$-mangostin at $24 \mathrm{~h}$ experienced inhibition of the development of the trophozoite stadium into schizon stadium. In case of developmental obstacles, the parasite will still make the process of taking hemoglobin, because in the trophozoit stadium the process of taking hemoglobin has increased. This further supports the mechanism of $\alpha$-mangostin against the degradation of the malaria parasite P. falciparum hemoglobin.

From the assay of inhibiton on development stadium and globin accumulation on the food vacuole of $P$. falciparum is known that compounds of $\alpha$-mangostin from $G$. tetrandra stem bark have a mechanism for inhibits hemoglobin degradation in line with research from Ignatushchenko that xanthones working on the process of inhibition of hemoglobin degradation. ${ }^{21}$

\section{CONCLUSION}

a-mangostin from $G$. tetrandra Pierre stem bark have mechanism action on inhibition the development stadium of the malaria parasite and inhibited of hemoglobin degradation processes occurring in the food vacuole of Plasmodium falciparum.

\section{ACKNOWLEDGEMENT}

Thanks to Faculty of Pharmacy Airlangga University, Institute of Tropical Diseases Airlangga University, Faculty of Mathematics and Natural Sciences Brawijaya University, Eijkman Institute, Jakarta.

\section{CONFLICT OF INTEREST}

We declare there is no conflict of interest.

\section{ABBREVIATIONS}

SDS-PAGE: sodium dodecyl sulfate- polyacrylamide gel electrophoresis; IC: Inhibitory Concentration; RBC: Red Blood Cells; DMSO: Dimethyl sulfoxide.

\section{REFERENCES}

1. Ersam T. Pemberdayaan Keanekaragaman Hayati Hutan Tropika : Fenolat Terprenilasi dari Artocarpus dan Garcinia (Nangka dan Manggis). National Seminar of Chemistry Proceeding. Universitas Negeri Surabaya, Surabaya: p. 2005;22-23.

2. Xia Y, Sun J. Synergistic inhibition of cell proliferation by combined targeting with kinase inhibitors and dietary xanthone is a promising strategy for melanoma treatment. Clin Exp Dermatol. 2017;43(2):149-57.

3. Márquez-Valadez B, Lugo-Huitrón $R$, Valdivia-Cerda $V$, Miranda-Ramírez LB, Pérez-De La Cruz V, González-Cuahutencos $\mathrm{O}$, et al. The natural xanthone $\alpha$-mangostin reduces oxidative damage in rat brain tissue. Nutr. Neurosci. 2009; 12(1):35-42

4. Sivaranjani M, Prakash M, Gowrishankar S, Rathna J, Pandian SK, Ravi AV. In vitro activity of alpha-mangostin in killing and eradicating Staphylococcus epidermidis RP62A biofilms. Appl Microbiol Biotechnol. 2017;101(8):3349-59.

5. Ibrahim MY, Hashim NM, Mariod AA, Mohan S, Abdulla MA, Abdelwahab SI, et al. $\alpha$-Mangostin from Garcinia mangostana Linn: An updated review of its pharmacological properties. Arab J Chem. 2016;9(3):317-29.

6. Laphookhieo S, Syers JK, Kiattansakul R, Chantrapromma K. Cytotoxic and antimalarial prenylated xanthones from Cratoxylum cochinchinense. Chem Pharm Bull. 2006;54(5);745-7.

7. Ersam T, Santosa M, Widyawaruyanti A. Kajian Bioaktivitas Dan Mekanisme Aksi Antimalaria Dari Senyawa Santon Pada Tumbuhan Wadung (Garcinia tetrandra Pierre), Research Final Report of HPTP. 2008. LPPM-ITS, Surabaya.

8. Sherman IW. Malaria, Parasite Biology, Pathogenesis and Pro tection. 2008. American Society for Micro biology Press, Washington, D.C., USA.

9. Fidock DA, Rosenthal PJ, Croft SL, Brun R, Nwaka S. Antimalarial drug discovery: Efficacy models for compound screening, Review, Nature. 2004;3(6):509-20.

10. Trager W, Jensen JB. Science. 1976;193(4254):673-5.

11. Lambros C, Vanderberg JP. Synchronization of Plasmodium falciparum erythrocytic stages in culture. The Journal of parasitology. 1979;418-20.

12. Rosenthal PJ, Wollish WS, Palmer JT, Rasnick D. Antimalarial Effects of Peptide Inhibitors of a Plamodium falciparum Cysteine Proteinase, Journal Clinical Investigation. 1991;88(5):1467-72.

13. Fattorusso E, Parapini S, Campagnuolo C, Basilico N, Taglialatela-Scafati O, Taramelli D. Activity against Plasmodium falciparum of cycloperoxide compounds obtained from the sponge Plakortis simplex. J Antimicrob Chemother. 2002;50(6):883-8.

14. Sherman IW. Malaria, Parasite Biology, Pathogenesis, and Protection, 1998, Washington, D.C : ASM press.1998.

15. Rosenthal PJ. Hydrolysis of Erythrocyte Proteins by Proteases of Malaria Parasites. Current Opinion in Hematology. 2002;9(2):140-5.

16. De Dominguez ND, Rosenthal PJ. Cysteine Protease Inhibitor Block Early Steps in Hemoglobin Degradation by Culture Malaria Parasite, Blood. 1996;87(10):4448-54.

17. Aulanni'am. Prinsip dan Teknik Analisis Biomolekul, Cetakan Pertama, 2004 Fakultas Pertanian Universitas Brawijaya Press, Malang, Indonesia. 2004:46-56.

18. Deutscher MP. Methods in Enzymology Vol. 182, Guide to Protein Purification. 1990:380-92. Academic Press Inc., San Diego.

19. Rosenthal PJ. Plasmodium falciparum: Effects of Proteinase Inhibitors on Globin Hydrolysis by Cultured Malaria Parasites, Experimental Parasitology. 1995;80(2):272-81.

20. Rosenthal PJ. Hydrolysis of Erythrocyte Proteins by Proteases of Malaria Parasites. Current Opinion in Hematology. 2002;9(2):140-5.

21. Ignatushchenko MV, Winter RW, Dan Riscoe M. 2000. Xanthones As Ant Malaria Agents: Stadium Specificity, AM. J Trop Med Hyg. 2000;62(1):77-81.

Cite this article: Kuncoro $H$, Widyawaruyanti A, Ersam T. $\alpha$-Mangostin effect on inhibition development stadium and globin accumulation against Plasmodium falciparum. Pharmacog J. 2018;10(4):783-8. 
GRAPHICAL ABSTRACT

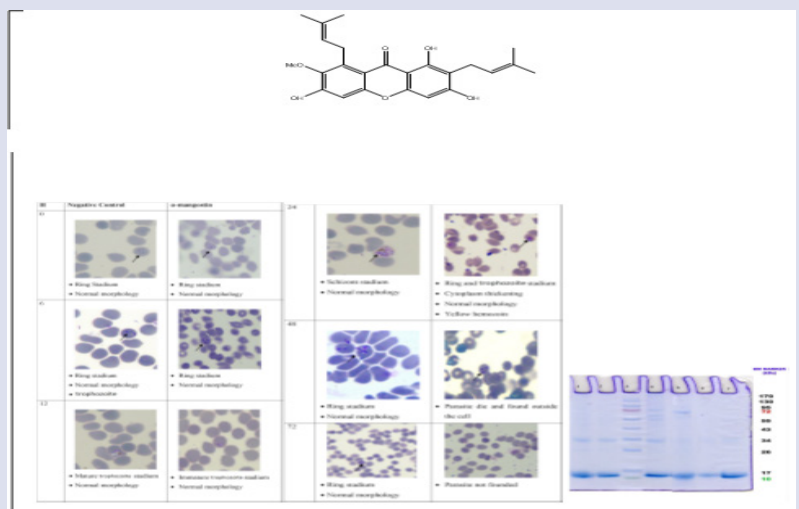

\section{SUMMARY}

- $\alpha$-Mangostin is one of isolated compound found from G. tetrandra.

- $\alpha$-Mangostin reported have antimalarial activity with $\mathrm{IC}_{50}$ value $0.5 \times 10-3 \mu \mathrm{M}$

- $\alpha$-Mangostin mechanism action on inhibition the development stadium of the malaria parasite and inhibited of hemoglobin degradation processes occurring in the food vacuole of Plasmodium falciparum

\section{ABOUT AUTHORS}

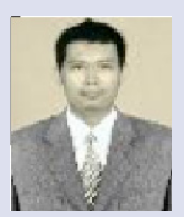

Hadi Kuncoro: A reseacher and academic staff at Fakultas Farmasi, Universitas Mulawarman. Samarinda, Indonesia

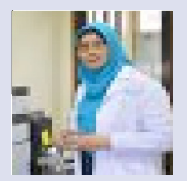

Aty Widyawruyanti: A researcher and academic staff at Faculty Of Pharmacy, Airlangga University, Surabaya, Indonesia

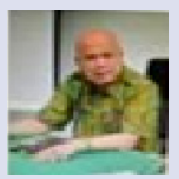

Taslim Ersam: A researcher and academic staff at Faculty of Mathematics and Natural Sciences, Institut Teknologi Sepuluh Nopember, Surabaya, Indonesia. 